\title{
Fecundity of Northeast Arctic Greenland halibut (Reinhardtius hippoglossoides)
}

\author{
Agnes Christine Gundersen \\ Møre Research, Section of Fisheries \\ P. O. Box 5075, N-6021 Ålesund, Norway \\ Olav Sigurd Kjesbu and Kjell Harald Nedreaas \\ Institute of Marine Research, P. O. Box 1870 \\ Nordnes, N-5024 Bergen, Norway \\ and \\ Anne Stene \\ Ålesund College, P. O. Box 5104 \\ 6021 Ålesund, Norway
}

\begin{abstract}
Relationships between fecundity (thousands) and total length $(\mathrm{cm}), F=1.155 \times 10^{-7} \times$ $L^{4.598}$ and fecundity (thousands) and round weight $(\mathrm{g})\left(F=2.539 \times 10^{-4} \times W^{1.439}\right)$ were established for Greenland halibut in the Northeast Atlantic, based on a total of 95 ovaries collected near the Bear Island in the Barents Sea, in September 1996. The potential fecundity ranged from 6800 to 70500 eggs per female. The Greenland halibut were in the total length range $48-80 \mathrm{~cm}$. The Greenland halibut were maturing with ovaries containing vitellogenic oocyte sized about $2-4 \mathrm{~mm}$ in diameter, visual to the naked eye.
\end{abstract}

Key words: Atlantic Ocean, Barents Sea, eggs, fecundity, Greenland halibut

\section{Introduction}

Greenland halibut (Reinhardtius hippoglossoides Walbaum) in the Norwegian and Barents Sea is distributed mainly on the continental slope off Norway from $62^{\circ} \mathrm{N}$ to the regions north of Spitsbergen. It is observed down to $1400 \mathrm{~m}$. In other parts of the Atlantic, Greenland halibut is observed down to $2000 \mathrm{~m}$ (Boje and Hareide, 1993). Greenland halibut is described as a borealarctic species and is mainly found at temperatures between $-1^{\circ} \mathrm{C}$ and $4{ }^{\circ} \mathrm{C}$. Recent studies on the spawning biology of Northeast Arctic Greenland halibut conclude that the main spawning season is from November to mid-January. Peak spawning is in December (Albert et al., MS 1998).

The population of Greenland halibut in the Northeast Arctic constitutes a separate management unit in the ICES management system. In the late1980s a drop was observed in the Northeast Arctic Greenland halibut year-class indices, derived from the regular 0-group and juvenile surveys. At the same time a historic low spawning stock biomass was observed (Hylen and Nedreaas, 1995; Smirnov, 1995). During the same time period, the importance of Greenland halibut as a commercial fish species increased. There was also a decrease in the commercial catch per unit of effort (CPUE) and all this led to strong regulations including a fishing ban north of $71^{\circ} 30^{\prime} \mathrm{N}$ from 1992.

Studies of fish reproduction, including oocyte production of the spawning stock, and stockrecruitment relationships are basic issues in the precautionary approach to fisheries management. Potential fecundity, which is defined as the number of oocytes developing in a female for the following spawning season (Bagenal, 1978) is important for obtaining data on population stability and year-class strength. Generally, deepwater species along with Arctic and Antarctic species produce fewer and bigger oocytes than related boreal species (Marshall, 1953). Fecundity is usually non-linearly related to total fish length and weight; the relations are usually allometric (Bagenal, 1978). 
Little work has been done on Greenland halibut fecundity, particularly in the Northeast Atlantic. Millinsky (1944) estimated fecundity of two Greenland halibut females in the Barents Sea. In East-Greenland waters a fecundity-length relationship is presented for 1996 (Rønneberg et al., MS 1998). In the Northwest Atlantic a few investigations on Greenland halibut have been conducted. Lear (1970) examined 45 females from the Newfoundland-Labrador area, Bowering (1980) 153 females from Southern Labrador and the Southeastern Gulf of St. Lawrence, and Jensen (1935) one female in West-Greenland waters. Serebryakov et al. (1992) give reports on fecundities in the Davis Strait near the Baffin Island and Labrador in the years $1975-80$ and $1987-88$.

Because of the lack of knowledge on potential fecundity of Greenland halibut in the Northeast Arctic, an individually based study was conducted in 1996. This paper describes the results from this study, and the primary objectives were to establish relationships between fecundity and length, and between fecundity and weight of Northeast Arctic Greenland halibut.

\section{Materials and Methods}

The ovaries were collected in September 1996, from fish caught by gillnets and longlines on the continental slope west of Bear Island (Fig. 1). The total sample consisted of 95 females randomly chosen from the catches. The females were maturing with oocyte diameters of 2-4 mm (naked eye). The fish were frozen at sea. After the survey the ovaries were preserved in $3.6 \%$ phosphate buffered formaldehyde.

For the fecundity study, the gravimetric method described by Bagenal and Braum (1978) was used. The procedure for estimating the number of oocytes in an ovary was to measure the total weight of the ovary after fixation, collect 4 subsamples and store the samples in $70 \%$ ethanol. A raising factor $\left(R_{x y}\right)$ for each subsample based on subsample weight and ovary weight was established (i), the number of oocytes in two of the samples was counted, and the total number of oocytes (defined as the fecundity) in the ovary was estimated (ii). The mean fecundity of the two samples was used as an estimate of fecundity for the individual. If the coefficient of variation $(\mathrm{CV})$ (iii) between the two samples exceeded $5 \%$, the two other samples were counted and

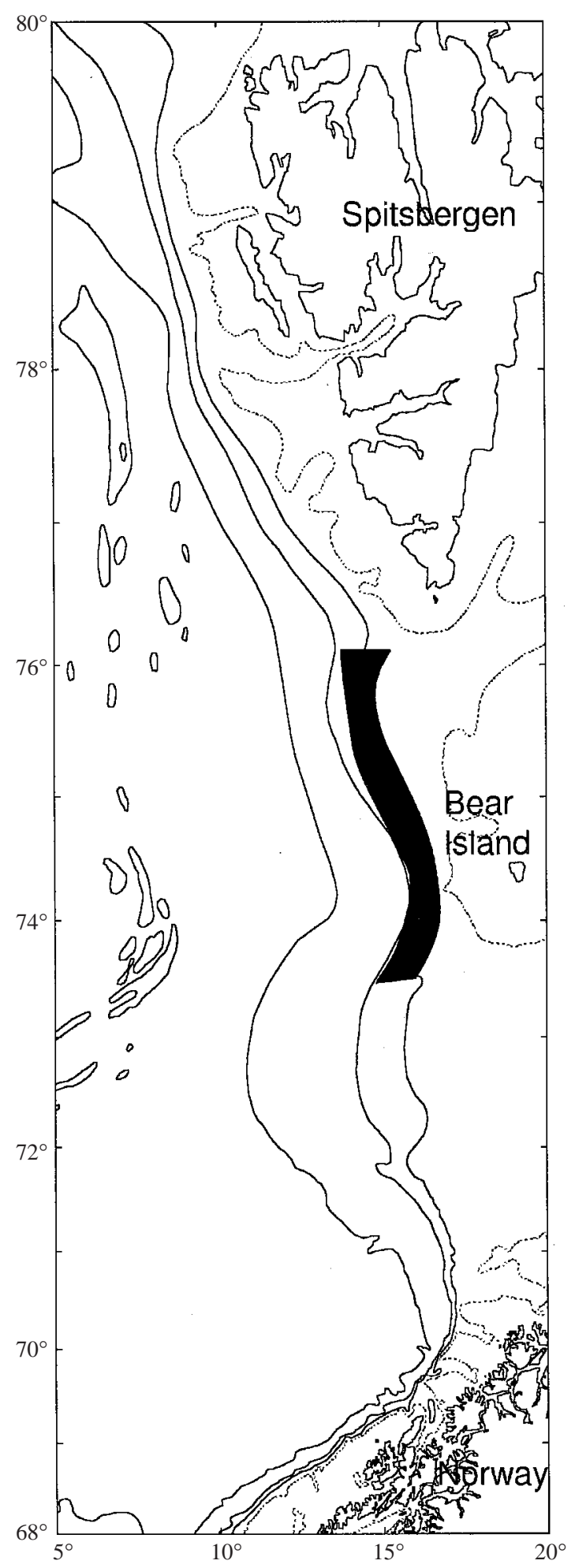

Fig. 1. Sampling areas for Greenland halibut used in this fecundity study. Samples were taken during the Autumn Survey conducted by the Institute of Marine Research, Bergen in 1996, west of the Bear Island. The $200 \mathrm{~m}(\cdots), 500 \mathrm{~m}, 1000 \mathrm{~m}$, and $1500 \mathrm{~m}$ depth contours are shown. 
used in the analyses. The oocytes were counted using a binocular microscope.

Raising factor was defined as (i):

$$
\text { (i) } R_{x y}=G W_{x} / S W_{\mathrm{xy}}
$$

$R_{\mathrm{xy}}=$ Raising factor for ovary $x$ and subsample $y, G W_{x}=$ gonad weight after fixation of ovary $x$, and $S W_{x y}=$ subsample weight of ovary $x$, subsample $y$.

Fecundity was estimated by the equation (ii):

$$
\text { (ii) } F_{\mathrm{xy}}=R_{x y} \times N_{\mathrm{xy}}
$$

$F_{\text {xy }}=$ fecundity of ovary $x$, subsample $y, R_{x y}=$ raising factor for ovary $x$ and subsample $y$, and $N=$ number of oocytes counted in ovary $x$, subsample $y$.

The coefficient of variation $(C V)$ expressed as $\%$ is the standard deviation (std) of the estimates divided by the mean fecundity $\left(F_{\text {mean }}\right)$ (Sokal and Rohlf, 1995).

$$
\text { (iii) } C V=(\operatorname{std} \times 100 \%) / F_{\text {mean }}
$$

The gonadosomatic index (GSI) is often used to describe the maturity state of the female, and it is traditionally defined as the ratio between the gonad weight $(G W)(g)$ and the total weight $(W)(g)$ of the fish (iv). Fedorov (1968) assumed that Greenland halibut prior to spawning undergo an increase in gonad weight, and that spawning is likely to occur when GSI is reaching a level of 15$18 \%$. Relationship between GSI and total length was established using regression analyses (log-logtransformation).

$$
\text { (iv) } G S I=(G W \times 100 \%) / W
$$

Relations between fecundity and liver index ( $H S I=$ hepatosomatic index $)$ were established using regression analyses (log-log-transformation). $H S I$ is defined as the ratio between the liver weight $(L W)(g)$ and total weight $(W)(g)$ of the fish $(v)$. Liver weight was obtained from only 37 of the 95 females, due to damage to the liver of some of the fish during freezing.

(v) $H S I=(L W \times 100 \%) / W$

Subsamples of $1.7 \mathrm{~g}$ were used in the analyses to get a $C V$ below $5 \%$. Three types of oocytes were observed. Vitellogenic oocytes, which appeared opaque in the microscope were defined as G1. This group was assumed to become spawning oocytes in a few months. Oocytes of significant smaller diameter with yolk appeared more transparent in the microscope with a defined "dark" nucleus. This group was defined as G2. In the microscope the G1 and $\mathrm{G} 2$ group were easily separated. Small, fully transparent, previtellogenic oocytes were defined as $\mathrm{R}$ (recruit group). The fecundity estimate of a female is based on the number of G1 oocytes. As the ovaries had been frozen, oocyte diameter was not recorded.

Homogenity of the oocyte distribution in an ovary was tested, by analysing four subsamples from each of four different sections in an ovary. This analysis was repeated for five different ovaries. The four sections investigated were the anterior, middle and posterior section of the right lobe and the middle section of the left lobe. Comparisons between the different sections within one lobe and between the two lobes were made for each of the five ovaries.

Relations between fecundity and length and fecundity and weight were established using loglog-transformed regression.

\section{Results}

The fecundity of the five chosen ovaries in the homogenity test varied from 20000 to 35000 (Table 1 ). The total length of the females used ranged 61$70 \mathrm{~cm}$. A comparison of the middle sections of the two lobes within each ovary indicated a minor variability between the two lobes (Table 2). No systematic trend was, however, observed. $C V$ of the right and left middle section was in the range 1.3$5.5 \%$ and $1.9-5.5 \%$, respectively. Between the three sections within the right lobe some variation was observed (Table 1), but no systematic trend was found. Therefore, subsamples from the middle section of the right lobe were assumed representative for the ovary, and the oocyte counts were based on subsamples taken in this section.

Total length of the 95 sampled Greenland halibut females ranged from $48 \mathrm{~cm}$ to $80 \mathrm{~cm}$, and the mean length was $65.2 \mathrm{~cm}(\mathrm{std}=6.0)$. Potential fecundity estimates ranged from 6800 to 70500 oocytes per female. Mean fecundity was 28100 oocytes $($ std $=13.7)$. 
TABLE 1. Mean fecundity in thousands $\left(F_{\text {mean }}\right)$ and coefficient of variation in percentage $(C V)$ for five Greenland halibut ovaries studied for homogenity. From each section four samples were analysed. $\mathrm{L}-\mathrm{M}=\mathrm{left}$ lobe middle section, $\mathrm{R}-\mathrm{A}=$ right lobe anterior section, $\mathrm{R}-\mathrm{M}=$ right lobe middle section, and $\mathrm{R}-\mathrm{P}=$ right lobe posterior section.

\begin{tabular}{|c|c|c|c|c|c|c|c|c|}
\hline \multirow[b]{2}{*}{ Ovary } & \multicolumn{2}{|c|}{$\mathrm{L}-\mathrm{M}$} & \multicolumn{2}{|c|}{$\mathrm{R}-\mathrm{A}$} & \multicolumn{2}{|c|}{$\mathrm{R}-\mathrm{M}$} & \multicolumn{2}{|c|}{$\mathrm{R}-\mathrm{P}$} \\
\hline & $F_{\text {mean }}$ & $C V$ & $F_{\text {mean }}$ & $C V$ & $F_{\text {mean }}$ & $C V$ & $F_{\text {mean }}$ & $C V$ \\
\hline $\mathrm{A}-70 \mathrm{~cm}$ & 32.6 & 4.5 & 32.5 & 2.1 & 32.3 & 2.5 & 27.7 & 5.4 \\
\hline $\mathrm{B}-62 \mathrm{~cm}$ & 23.0 & 1.9 & 28.1 & 9.5 & 23.7 & 3.3 & 28.2 & 9.2 \\
\hline$C-67 \mathrm{~cm}$ & 30.3 & 3.9 & 23.8 & 1.9 & 33.0 & 4.5 & 23.4 & 2.1 \\
\hline $\mathrm{D}-61 \mathrm{~cm}$ & 20.6 & 5.5 & 32.9 & 3.7 & 19.8 & 5.5 & 33.9 & 1.6 \\
\hline$E-65 \mathrm{~cm}$ & 28.6 & 2.6 & 18.8 & 8.1 & 30.2 & 1.3 & 20.0 & 3.5 \\
\hline
\end{tabular}

TABLE 2. Homogenity within one ovary lobe of five Greenland halibut (see Table 1) represented as the right lobe mean based on three different subsample locations (anterior, middle and posterior section), and between the two lobes of the five ovaries, represented by samples taken in the middle section of the right and left lobe.

\begin{tabular}{lrrrrr}
\hline \hline & \multicolumn{5}{c}{ Ovary } \\
\cline { 2 - 6 } Homogenity comparisons & $\mathrm{A}$ & $\mathrm{B}$ & $\mathrm{C}$ & $\mathrm{D}$ & $\mathrm{E}$ \\
\hline Right lobe mean fecundity (1 000) & 30.8 & 23.6 & 33.2 & 19.5 & 30.5 \\
$C V(\%)$ & 8.2 & 2.4 & 3.4 & 6.0 & 5.6 \\
$\begin{array}{l}\text { Mean fecundity (1 000) of left } \\
\text { and right lobe (middle sections) }\end{array}$ & 32.5 & 23.3 & 31.4 & 20.1 & 29.4 \\
$C V(\%)$ & 3.4 & 2.9 & 6.1 & 5.6 & 3.5 \\
\hline
\end{tabular}

The relationship between fecundity $(F)$ and length $(L)$ (Fig. 2) is:

$$
\begin{gathered}
F=1.155 \times 10^{-7} \times \mathrm{L}^{4.598} \\
\left(r^{2}=0.68, p<0.005\right)
\end{gathered}
$$

The fecundity is expressed in thousands and the length is given as total length in $\mathrm{cm}$.

The relationship between fecundity $(F)$ and weight $(W)$ (Fig. 3) is:

$$
\begin{gathered}
F=2.539 \times 10^{-4} \times W^{1.439} \\
\left(r^{2}=0.77, p<0.005\right)
\end{gathered}
$$

The fecundity is expressed in thousands and the total weight is in grams.

A comparison between fecundity for Greenland halibut from different areas based on the results in this paper and previous published results is shown in Fig. 4.
Gonadosomatic index (GSI) was in the range $1.9-13.5 \%$, with a mean of $7.5 \%(\mathrm{std}=2.2, \mathrm{~N}=$ 95). Hepatosomatic index (HSI) was in the range $0.3-4.6 \%$, with a mean of $2.4 \%(\operatorname{std}=1.1, N=37)$. No significant relation between HSI and total fish length was observed $\left(r^{2}=0.03, N=37, p>0.05\right)$. The regression between fecundity and HSI was not significant $\left(r^{2}=0.10, N=37, p>0.05\right)$ (Fig. 5).

\section{Discussion}

Greenland halibut included in this fecundity study were sampled in mid September 1996. Sampling of the ovaries was random, conducted from one longline setting and one gillnet setting. The samples were collected over a short period of time. This means that the length and weight measurements should not be influenced by growth in the time of sampling.

In the ovaries investigated in this paper, three groups of oocytes were observed. The oocytes were 


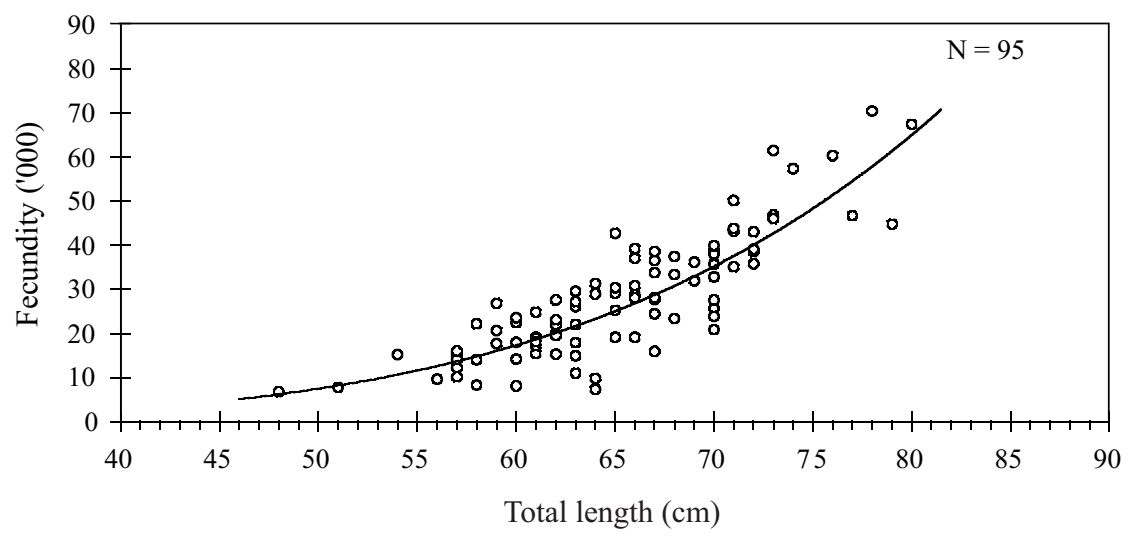

Fig. 2. Fecundity $(F)$ (in thousands) of Northeast Arctic Greenland halibut related to total length $(L)(\mathrm{cm})$ given as $F=1.155 \times 10^{-7} \times L^{4.598}\left(r^{2}\right.$ $=0.68)$.

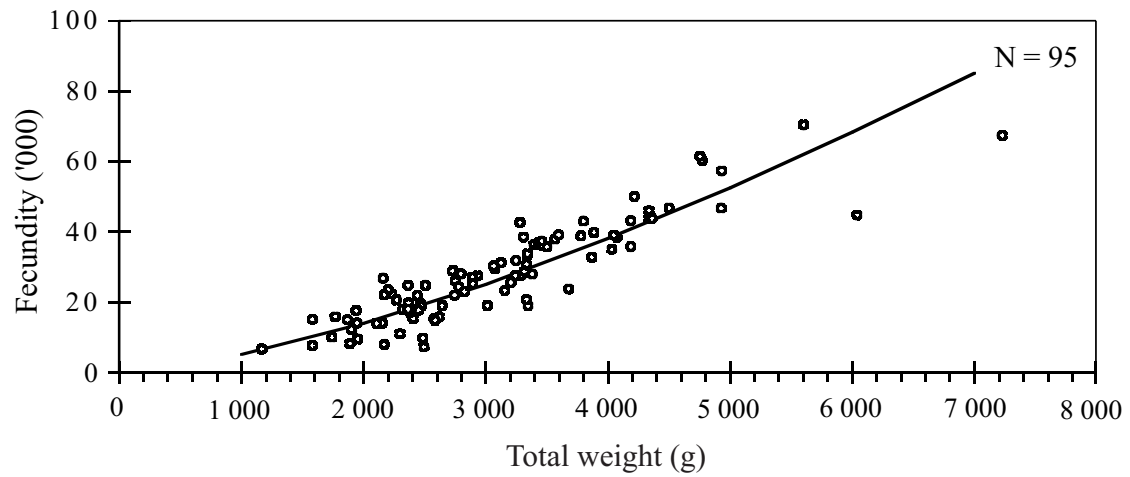

Fig. 3. Fecundity $(F)$ (in thousands) of Northeast Arctic Greenland halibut related to total weight $(W)(\mathrm{g})$ given as $F=2.539 \times 10^{-4} \times W^{1.439}\left(r^{2}=\right.$ $0.77)$.

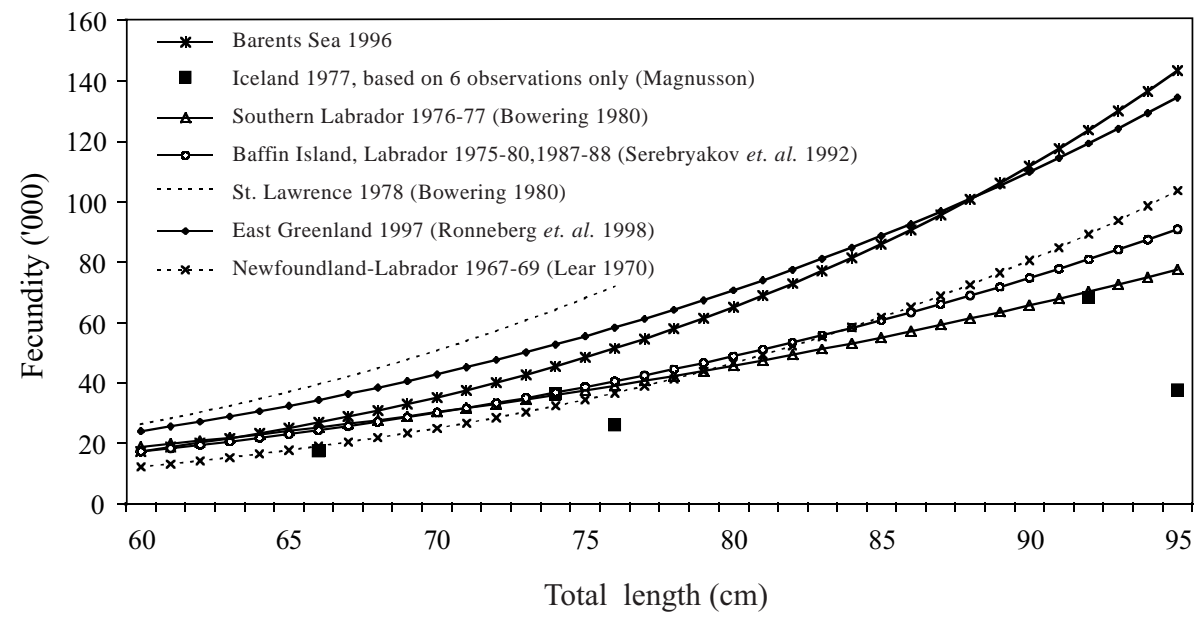

Fig. 4. Fecundity (in thousands) of Greenland halibut from different geographic areas. Comparisons are based on the respective fecundity-length-relationships presented in the cited papers. 


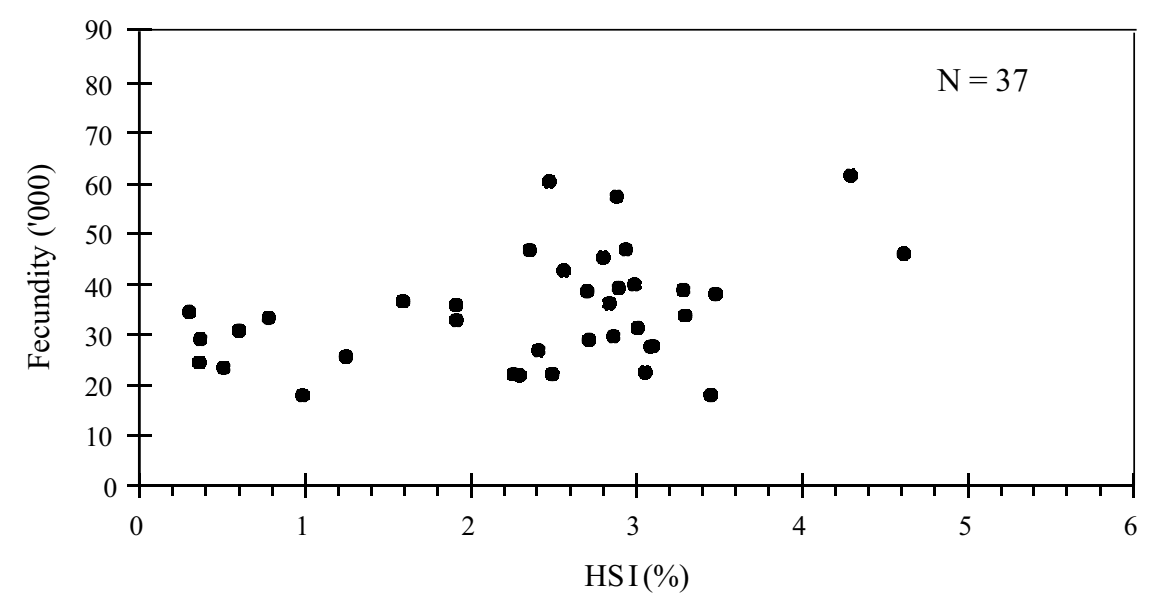

Fig. 5. Fecundity (in thousands) of Northeast Arctic Greenland halibut related to hepatosomatic index \% (HSI).

easily classified and there were no problems separating the vitellogenic oocytes (G1) from the early maturing (G2), implying that the fecundity estimates are not biased due to overlapping of oocytes groups from different maturity groups. This is also verified by data on oocyte diameter from the same area in September 1997 (Gundersen, Møre Research, Ålesund, Norway, unpubl. data). Oocyte diameters indicate two distinct peaks for G1 and G2 oocytes, the G1 group being larger than 1100 microns.

Data on gonadosomatic indices (GSI) for Northeast Arctic Greenland halibut sampled monthly on the spawning grounds in 1997 show an increase in GSI from a minimum in February-April until spawning commenced in November (Gundersen, Møre Research, Ålesund, Norway, unpubl. data). Fedorov (1968) described the maturation of Greenland halibut based on GSI, and assumed that GSI for Greenland halibut prior to spawning reaches a level of $15-18 \%$. GSI values from our study were in the range $1.9-13.5 \%$, indicating that the maturity process is in progress in the period of sampling, but that spawning had not yet begun.

Investigations carried out in the Northeast Arctic in 1996-98, concluded that the main spawning period of Greenland halibut is from November to mid January, with a peak in December (Albert et al., MS 1998). The oocytes of the ovary seem to be shed at the same time, indicating no batch spawning (Stene et al., MS 1998). This means that September is a good time of sampling, just prior to spawning, but still not overlapping with the spawning period.

The fecundity of Greenland halibut showed a slightly better relationship with weight than with length, however, both relationships were significant $(p<0.005)$. Prior to the study, only a few females have been studied with respect to fecundity of Greenland halibut in the eastern part of the Northeast Atlantic. Millinsky (1944) estimated a fecundity of 28000 and 33000 for two Greenland halibut females in the Barents Sea. This is within the same range as the results of the present study.

In the Northwest Atlantic a few investigations on the fecundity of Greenland halibut have been conducted. In the Newfoundland-Labrador area, the fecundity was in the range 15000 to 215000 (Lear, 1970). A curved relationship based on 45 females collected over the period 1967-69, was established. Bowering (1980) compared the results obtained by Lear (1970) to fecundity samples collected in the Southern Labrador and the Southeastern Gulf of St. Lawrence in 1976-78. Using the relationship between fecundity and length presented in this paper, a $70 \mathrm{~cm}$ female Greenland halibut in the Barents Sea is likely to produce 35000 oocytes on average. In the Labrador area, the fecundity-length-relationship indicated that a $70 \mathrm{~cm}$ long female would produce 30000 oocytes on average. In the Gulf of St. Lawrence a $70 \mathrm{~cm}$ female is predicted to produce 50000 oocytes on average (Bowering, 1980). This may indicate a geographic variation in fecundity (see Fig. 4). 
Jensen (1935) estimated the fecundity of one female $(101 \mathrm{~cm})$ in West-Greenland waters to 300000 oocytes. In East Greenland waters fecundity was estimated to be in the range 32 000277000 oocytes (Rønneberg et al., 1998). This is a considerably wider range of fecundity than observed for the present study in the Barents Sea. However, similar to the work of Lear (1970) from the Southern Labrador these refer to Greenland halibut in a wider length range, including larger fish than in the present study.

In an area west of Iceland, ovaries from 5 Greenland halibut females were analysed for fecundity in March 1977 (Magnusson, MS 1977). The fecundity was in the range $17500(66 \mathrm{~cm})$ to 42200 $(74 \mathrm{~cm})$ oocytes. The largest female was $96 \mathrm{~cm}$, showing a fecundity of 37600 oocytes. The oocyte diameter (unpreserved) was in the range 2.28-4.46 $\mathrm{mm}$, with an average of $3.38 \mathrm{~mm}$. It is also mentioned that a female $(92 \mathrm{~cm})$ caught north of Iceland in June had a fecundity of 68300 (average oocyte diameter $3.95 \mathrm{~mm}$ ). These results indicate a slightly lower fecundity in Icelandic waters compared to the present study (Fig. 4). During the sampling of the Icelandic ovaries spawning was reported in the investigated area. This may have influenced the fecundity estimates, and may be a reason for the slightly lower estimate compared to other areas.

The fecundity estimates presented by Lear (1970) were based on oocyte diameters in the range $0.5-2.6 \mathrm{~mm}$. When comparing this range to the oocyte distribution observed in September 1997 in the Barents Sea (first authors comment), and in East Greenland waters in 1997 (Rønneberg et al., 1998), it is likely that Lear's estimates also include some oocytes in the G2 group, as defined in this study. That is, of course, if the maturity process is similar in the two areas. The oocyte diameter range of the studies by Bowering (1980) is not described. Serebryakov et al. (1992) used ovaries in maturity stage III and IV with no further reference to oocyte diameter.

In the fecundity-length-relationship the exponent $b$ was estimated to be 4.598. Bagenal (1978) stated that the exponent usually ranges from 2.3 to 5.3 , most often being a little above 3 . The exponent $b$ derived here is in the interval described by Bagenal (1978), but it is slightly higher than the corresponding exponent reported for Greenland halibut in other areas, implying a higher increase in fecundity for the bigger females. Rønneberg et al. (1998) estimated the exponent for Greenland halibut in East Greenland waters to be 3.75. For Greenland halibut in the Northwest Atlantic the exponent is estimated to be 3.08 (Bowering, 1980), 3.62 (Serebryakov et al., 1992) and 4.66 (Lear 1970). In the Bering Strait, D'yakov (1978) estimated the exponent to be 2.58 .

Hepatosomatic index (HSI) was in the range $0.3-4.6 \%$. This is in the same range as observed for Greenland halibut in East Greenland waters in the above mentioned by Rønneberg et al. (1998). A significant relation between fecundity and HSI was not observed. Due to freezing of round fish at sea, only 37 individuals had liver of good shape when measuring the different variables in the laboratory. This means that the results concerning HSI in our study is based on few measurements, and it is therefore difficult to make a firm conclusion on the relation between fecundity and HSI.

\section{Acknowledgements}

The authors want to thank the Institute of Marine Research, Bergen, Norway for financing the study. The authors want to thank the staff of the vessels $M / S$ Vonar and M/S Husby Senior, the scientific staff of the Institute of Marine Research collecting the material and drawing the map, and O. Espe, Møre Research for thorough work in the laboratory. The authors also want to thank two anonymous reviewers for constructive comments on the manuscript.

\section{References}

AlBERT, O. T., E. M. NILSSEN, A. STENE, A. GUNDERSEN, and K. H. NEDREAAS. MS 1998. Spawning of the Barents Sea/Norwegian Sea Greenland halibut (Reinhardtius hippoglossoides). ICES C.M. Doc., No. O:22.

BAGENAL, T. B. 1978. Aspects of fish fecundity in ecology of freshwater fish production. Blackwell Scientific Publications: 75-102.

BAGENAL, T. B., and E. BRAUM. 1978. Eggs and early life history. In: IBP handbook. Methods for assessment of fish production in fresh waters, T. M. Bagenal (ed.), 3(7): 165-201.

BOJE, J., and N.-R. HAREIDE. MS 1993. Trial deepwater longline fishery in the Davis Strait, MayJune 1992. NAFO SCR. Doc., No. 53, Serial No. N2236, 6 p. 
BOWERING, W. R. 1980. Fecundity of Greenland Halibut (Reinhardtius hippoglossoides Walbaum), from southern Labrador and South-eastern Gulf of St. Lawrence. J. Northw. Atl. Fish. Sci., 1: 39-43.

D'YAKOV, Yu. P. 1978. The fecundity of the Greenland Halibut, Reinhardtius hippoglossoides (Pleuronectidae), from the Bering Sea. J. of Ichthyol., 2(5) 1982: 59-64.

FEDOROV, K. Y. 1968. Oogenesis and sexual maturity cycle of Greenland halibut. Trudy PINRO: 425-451.

HYLEN, A., and K. H. NEDREAAS. 1995. Pre-recruit studies of the North East Arctic Greenland halibut stock. In: Precision and relevance of pre-recruit studies for fishery management related to fish stocks in the Barents Sea and adjacent waters, Hylen, A (ed.) Proceeding of the sixth IMR-PINRO Symposium, Institute of Marine Research, Bergen 14-17 June 1994, 229-238 p.

JENSEN, A. S. 1935. The Greenland halibut (Reinhardtius hippoglossoides (Walb.)) its development and migrations. "Det Kongelige Danske Videnskabs Selskabs Skrifter, Natur-videnskabelig Mathematisk Afdeling" 9(VI/4): 35 p.

LEAR, W. A. 1970. Fecundity of Greenland Halibut (Reinhardtius hippoglossoides) in the Newfoundland-Labrador Area. J. Fish. Res. Board Can., 27(10): 1880-1882.

MAGNUSSON, J. V. MS 1977. Notes on eggs and larvae of Greenland halibut at Iceland. ICES C.M. Doc., No. F:47, 6 p.

MARSHALL, N. B. 1953. Egg size in Antarctic and deep-sea fishes. Evolution, 7: 328-341.

MILLINSKY, G. J. 1944. On the biology and the fisheries of the Reinhardtius hippoglossoides (Walbaum) of the Barents Sea. The Bottom Food-Fishes of the Barents Sea, 8: 375-387, Moscow.

RØNNEBERG, J. E., A. C. GUNDERSEN, and J. BOJE. MS 1998. Fecundity of Greenland halibut (Reinhardtius hippoglossoides) in East Greenland waters, July 1997. ICES C.M. Doc., No. O:26, 12 p.

SEREBRYAKOV, V. P., A. K. CHUMAKOV, and I. I. TEVS. 1992. Spawning Stock, Population Fecundity and Year-Class Strength of Greenland Halibut (Reinhardtius hippoglossoides) in the Northwest Atlantic. J. Northw. Atl. Fish. Sci., 14: 107-113.

SMIRNOV, O. V. 1995. Dynamics of Greenland halibut recruitment to the Norwegian-Barents Sea stock from 1984-1993 trawl survey data. In: Precision and relevance of pre-recruit studies for fishery management related to fish stocks in the Barents Sea and adjacent waters, Hylen, A (ed.) Proceeding of the sixth IMR-PINRO Symposium, Institute of Marine Research, Bergen 14-17 June 1994, 239-242 p.

SOKAL, R. R., and F. J. ROHLF. 1995. Biometry. The principles and practice of statistics in biological research. Third edition. W.H. Freeman \& Company, New York, 887 p.

STENE, A., A. GUNDERSEN, O. T. AlbERT, P. SOLEMDAL, and K. H. NEDREAAS. MS 1998. Early development of Northeast Arctic Greenland halibut (Reinhardtius hippoglossoides). ICES C.M. Doc., No. O:27. 